\title{
A mixture of trehalose derivatives mitigates the adverse effects of water deficits in maize: an analysis of photosynthetic efficiency
}

\author{
A.S. AMBRÓSIO*, J.A.N. PORTUGAL*, K.R.D. SOUZA*, L.C. SILVA**, D.F. DIAS**, \\ J.R. MANTOVANI***, P.C. MAGALHÃES", T.B. SOUZA ${ }^{\# \#, ~ a n d ~ T . C . ~ S O U Z A *,+~}$ \\ Institute of Nature Sciences, Federal University of Alfenas, P. O. Box 37130-001, Alfenas-MG, Brazil ${ }^{*}$ \\ Institute of Chemistry, Federal University of Alfenas, P. O. Box 37130-001, Alfenas-MG, Brazil ${ }^{* *}$ \\ Institute of Agricultural Sciences, José do Rosário Vellano University, P. O. Box 37132-440, Alfenas-MG, Brazil*** \\ Maize and Sorghum National Research Center, P. O. Box 151, 35701-970, Sete Lagoas-MG, Brazil\# \\ Departament of Pharmacy, Federal University of Ouro Preto, P. O. Box 35400-000, Ouro Preto-MG, Brazil \#\#
}

\begin{abstract}
This study tested a tosylated and azide trehalose derivative mixture for its ability to mitigate water deficit-induced stress in maize via photosynthetic efficiency analyses. The experiment was conducted in greenhouse pots, using a maize hybrid that is sensitive to drought. The mixture of derivatives $(28 \mathrm{mM})$ was applied with a hand sprayer. Plants containing five/six fully expanded leaves were subjected to water deficit stress for $12 \mathrm{~d}$, followed by rehydration. The derivative mixture increased the photosynthetic rate, electron transport rate, and photochemical quenching, and mitigated damage to photosystem II. Moreover, it led to anatomical modifications in the leaf that increased the photosynthetic rate. These results suggest that the trehalose derivative mixture mitigates stress-induced damage in the maize hybrid and may represent a new stimulant for water-deficit tolerance.
\end{abstract}

Additional key words: chlorophyll a fluorescence; gas exchange; leaf anatomy; stomatal density; Zea mays L.

\section{Introduction}

Water deficits are natural events that compromise cereal production; they are responsible for plant damage and cause agricultural crop losses of more than $80 \%$ (FAO et al. 2018). Maize is an important crop for human and animal consumption and serves as a raw material for other foods, medicines, and fuels. As such, the livelihood of many local farmers depends on successful maize production (Adiaha et al. 2016, Larkins 2017). The flowering (VT) and grain filling (R3) stages of maize are important, but the V5/V6 (five/six fully expanded leaves) vegetative stage is critical for the study of water deficit effects because floral differentiation occurs during this period (Magalhães and Durães 2006, Souza et al. 2016, Yan et al. 2016). Perdomo et al. (2017) observed photosynthesis limitations with water deficit at the stage V5/V6, which compromised the biochemical phase and was associated with a reduction in the activation of Rubisco enzyme. A reduction in water potential, transpiration rate, stomatal conductance, and dry matter was also observed at the same stage (Riboldi et al. 2016).

Under water-deficit conditions, plants reduce their photosynthetic activity and produce more reactive oxygen species (ROS), due to excess energy absorption and low consumption in the Calvin cycle (Zandalinas et al. 2018). The first response to low-water stress is stomatal closure, which decreases water loss to the atmosphere via transpiration. However, this also reduces the photosynthetic rate in plants (Lawson et al. 2018, Lawson and VialetChabrand 2019). Decreasing water absorption results in photoinhibition, with reduced photochemical quenching

\footnotetext{
Received 27 January 2020, accepted 27 March 2020.

${ }^{+}$Corresponding author; phone: +553 537019 683, e-mail: thiagonepre@hotmail.com

Abbreviations: CT - cuticle thickness; $E$ - transpiration rate; ET - epidermis thickness; ETR - electron transport rate; $\mathrm{F}_{0}-$ minimal fluorescence yield of the dark-adapted state; $\mathrm{F}_{0}{ }^{\prime}$ - minimal fluorescence yield of the light-adapted state; $\mathrm{F}_{\mathrm{m}}-$ maximal fluorescence yield of the dark-adapted state; $F_{m}{ }^{\prime}-$ maximal fluorescence yield of the light-adapted state; $F_{s}-$ constant fluorescence; $F_{v}-$ variable fluorescence; $g_{\mathrm{s}}$ - stomatal conductance; IRRI - irrigated; LBT - limb thickness; NPQ - nonphotochemical quenching; P - phloem area; PD - polar diameter of stomata; $P_{\mathrm{N}}$ - photosynthetic rate; $\mathrm{q}_{\mathrm{p}}$ - photochemical quenching; $\mathrm{SD}$ - stomatal density; $\mathrm{SF}$ - stomatal functionality; WD - water deficit; WD+TD - water deficit with the mixture of trehalose derivatives; WD+TRE - water deficit with trehalose; WUE - water-use efficiency; $\mathrm{Y}_{\mathrm{II}}$ - effective photochemical quantum yield of PSII; $\mathrm{Y}_{\mathrm{NO}}$ - quantum yield of nonregulated energy dissipation of PSII; $\mathrm{Y}_{\mathrm{NPQ}}$ - quantum yield of regulated energy dissipation of PSII.

Acknowledgements: This project was financially supported by the National Scientific and Technological Development Council (CNPq) (Process 423584/2016-2, Universal call 01/2016), the Coordination for the Improvement of Higher Education Personnel, Brazil (CAPES) (Funding Code 001), and a research productivity grant from CNPq (modality PQ, category 2, given to T.C. Souza - Process: 304421/2018-9).
} 
and increased nonphotochemical quenching. In this case, the plant allocates less energy to photosynthesis and dissipates more energy as heat or ROS (Liu et al. 2012, Hazrati et al. 2016, Mathobo et al. 2017).

Parameters linked to photosynthetic efficiency, such as leaf gas exchange (e.g., photosynthesis, stomatal conductance), chlorophyll a fluorescence (e.g., quenching evaluation), and leaf anatomy (e.g., stomatal density, limb, epidermis, and cuticle thickness), are efficient morphophysiological tools to differentiate the variable sensitivities of plant genotypes to water deficits (Jabeen et al. 2008, Efeoğlu et al. 2009, de Souza et al. 2013, dos Reis et al. 2019).

Technological development is necessary to devise new methods to overcome the stress-induced barriers to agriculture. One such development is biostimulants substances or microorganisms that increase plant growth via improved nutrient absorption, abiotic stress tolerance, and product quality (Calvo et al. 2014, du Jardin 2015). The application of tolerance-inducing biostimulants aims to improve plant physiology by increasing leaf water status, antioxidant enzymatic activity, and photosynthetic activity (Souza et al. 2013, Kałużewicz et al. 2017). In maize, several biostimulants have been used and include naturally produced and laboratory-synthesized products, such as silicon, chitosan, abscisic acid, ascorbic acid, and trehalose (Ali and Ashraf 2011, Van Oosten et al. 2017, Yamauchi 2018, Rabêlo et al. 2019).

The exogenous application of trehalose to maize reduces the damage caused by water stress and increases the physiological parameters, biomass, and grain yield (Ali and Ashraf 2011, Zhou et al. 2014). Trehalose ( $\alpha$-D-glucopyranosyl-1,1- $\alpha$-D-glucopyranoside) is an unreduced disaccharide and widely occurring natural sugar (found in mushrooms, shrimps, insects, bacteria, and plants) with no toxicity (Bosch et al. 2016, Mnif and Ghribi 2016). Previous studies have explored the relationship between trehalose and water-deficit tolerance in plants, while others have investigated the synthesis of trehalose derivatives within the healthcare industry (Hsieh et al. 2015, Oliveri et al. 2016). However, many aspects of trehalose use remain unexplored. Here, we investigated the application of new trehalose derivatives (tosylated trehalose and azide trehalose) in agriculture.

The trehalose derivatives were planned in order to be obtained easily and in large quantities, considering the scalability of the process for industry. Furthermore, the derivatives had higher lipophilicity than that of trehalose in order to increase the permeability of maize leaves. Another desired feature is that these derivatives if they are ingested (a part that may be retained in the plant material) do not exert action on man. For a preliminary assessment using the SwissADME website (Daina et al. 2017), the pharmacokinetic parameters in silico were calculated and all substances have low absorption in the gastrointestinal tract and in the skin. The effects of semisynthetic derivatives of trehalose in plants have not been studied. This study aimed to investigate the photosynthetic efficiency of maize plants under water deficit sprayed with a tosylated and azide trehalose derivatives mixture.

\section{Materials and methods}

Synthesis of biomolecules: The trehalose (1) derivatives used in the study were: tosylated trehalose (2), the 6-O[(4-methylphenyl)sulfonyl]- $\alpha$-D-glucopyranoside from 6-O-[(4-methylphenyl)sulfonyl]- $\alpha$-D-glucopyranosyl of $\mathrm{WM}=650.13 \mathrm{~g} \mathrm{~mol}^{-1}$ and azide trehalose (3), the 6-azido6-deoxy- $\alpha$-D-glucopyranoside from 6-azido-6-deoxy$\mathrm{D}$-glucopyranosyl of $\mathrm{WM}=392.13 \mathrm{~g} \mathrm{~mol}^{-1}$ (Fig. 1). For the synthesis of the derivatives, trehalose (Vetec-Sigma $\left.{ }^{\circledR}\right)$ (1) was initially reacted with $p$-toluenesulfonyl chloride (tosyl chloride) in anhydrous pyridine, followed by the addition of acetic anhydride to form intermediate (4) (Menger and Mbadugha 2001). Intermediate derivative azide (5) was produced by the reaction of intermediate (4) with sodium azide in pyridine (Menger and Mbadugha 2001). Finally, the deprotection of hydroxyls by the basic hydrolysis of acetyl esters with potassium hydroxide in methanol formed unprotected derivatives (2) and (3) (de Souza et al. 2015) (Fig. 1). Details of the intermediate derivative reactions and the trehalose derivatives and their chemical characteristics are presented in supplement.

Local conditions and plant material: The experiment was conducted in a greenhouse ( $\mathrm{min} / \max$ temperature: $20 / 30^{\circ} \mathrm{C}$; average relative humidity: $74.4 \%$ ) at the Santa Clara Educational Unit of the Federal University of Alfenas (UNIFAL-MG), in Alfenas, Minas Gerais (altitude: $818 \mathrm{~m}$; $\left.21^{\circ} 25^{\prime} \mathrm{S}, 45^{\circ} 58^{\prime} \mathrm{W}\right)$. Global radiation, measured inside the greenhouse with a radiometer (Instrutherm/MES-100), averaged $900 \mathrm{~W} \mathrm{~m}^{-2}$ at noon.

The plants were grown in $10 \mathrm{dm}^{3}$ pots with an oxisol (Santos et al. 2018) soil surface layer (0-0.2 m). No liming was required. Fertilization followed chemical analysis of the soil; at the time of planting, $11 \mathrm{~g}$ of simple superphosphate $\left(18 \% \mathrm{P}_{2} \mathrm{O}_{5}\right)$ was applied to each pot. The effects of water deficit are best observed on nontolerant plants, so we planted four seeds per pot of the water deficit-sensitive maize hybrid BRS 1030 (de Souza et al. 2013) from the Embrapa Breeding Program (Maize and Sorghum National Research Center). After emergence, the pots were thinned to two plants per pot and fertilized with a solution of $1 \mathrm{mg}$ (boron) $\mathrm{dm}^{-3}$ [B; sourced from boric acid $\left.\left(\mathrm{H}_{3} \mathrm{BO}_{3} ; 11 \% \mathrm{~B}\right)\right]$ and $2 \mathrm{mg}(\mathrm{Zn}) \mathrm{dm}^{-3}$ [sourced from zinc sulfate $\left.\left(\mathrm{ZnSO}_{4} ; 20 \% \mathrm{Zn}\right)\right]$. During the experiment, fertilization with nitrogen $(\mathrm{N})$ and potassium $(\mathrm{K})$ was performed weekly after thinning via a solution of 50 $\mathrm{mg}(\mathrm{N}) \mathrm{dm}^{-3}$ and $117 \mathrm{mg}(\mathrm{K}) \mathrm{dm}^{-3}$ [sourced from urea $(45 \% \mathrm{~N})$ and potassium chloride $(\mathrm{KCl} ; 50 \%$ potassium oxide, $\left.\mathrm{K}_{2} \mathrm{O}\right)$ ] (Raij et al. 2001).

Water deficit imposition, application of trehalose and its derivatives, and the experimental design: The soil water content was monitored by weighing the pots in the morning $(08: 00 \mathrm{~h})$ and evening $(18: 00 \mathrm{~h})$ on a $25-\mathrm{kg}$ digital scale (200SS, Black Bull, São Paulo, Brazil). Water was added to maintain the water contents and pot masses at field capacity (FC) during the preexperimental period (i.e., before water deficit). The FC calculations were performed using an Excel spreadsheet. 


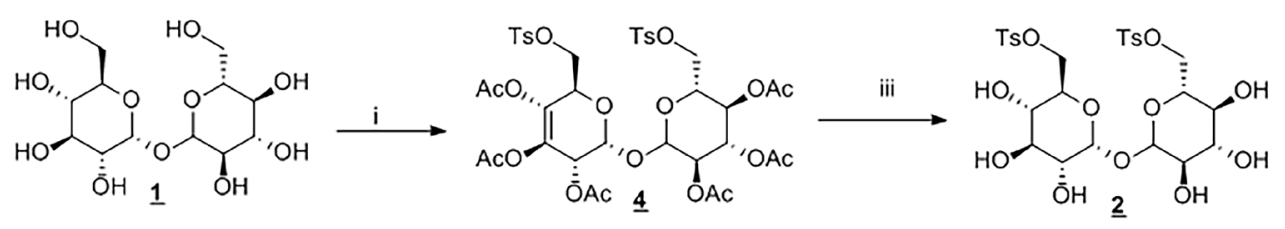

Reagents: i- 1) TsCl, Py; 2) $\mathrm{Ac}_{2} \mathrm{O}$; ii$\mathrm{NaN}_{3}$, DMF; iii- $\mathrm{MeOH}, \mathrm{KOH}$

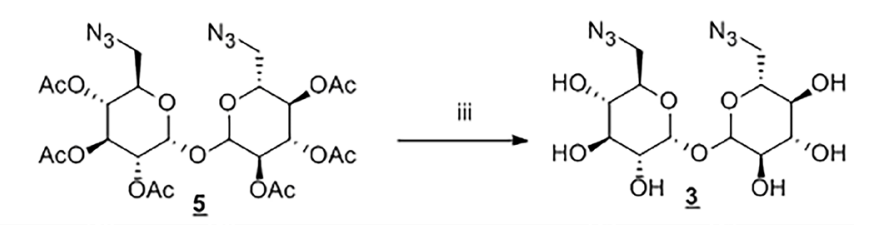

Fig. 1. Synthesis reactions of the trehalose derivatives. The figure shows the chemical structures of trehalose (1); tosylated trehalose, 6- $O$-[(4-methylphenyl)sulfonyl]- $\alpha$-D-glucopyranoside from 6-O-[(4-methylphenyl)sulfonyl]- $\alpha$-D-glucopyranosyl (2); azide trehalose, 6-azido-6-deoxy- $\alpha$-D-glucopyranoside from 6-azido-6-deoxy-D-glucopyranosyl (3); and the intermediate derivatives 2,3,4-tri- $O$-acetyl6-O-[(4-methylphenyl)sulfonyl]- $\alpha$-D-glucopyranoside from 2,3,4-tri- $O$-acetyl-6- $O$-[(4-methylphenyl)sulfonyl]- $\alpha$-D-glucopyranosyl (4); and 2,3,4-tri- $O$-acetyl-6-azido-6-deoxy- $\alpha$-D-glucopyranoside from 2,3,4-tri- $O$-acetyl-6-azido-6-deoxy- $\alpha$-D-glucopyranosyl (5).

In the irrigated (IRRI) treatment, daily irrigation maintained the soil at 70\% field capacity (FC), while in the water deficit (WD) treatment, irrigation supplied only $55 \%$ of the total available water. Plants at the V5 developmental stage of the WD treatment group were irrigated with a smaller water volume $2 \mathrm{~d}$ before the treatment to reach $55 \% \mathrm{FC}$. Thus, $12 \mathrm{~d}$ of water deficit and stress began at the stage V5/V6 - the phase most susceptible to water stress (Magalhães and Durães 2006).

The base water potential reflects the balance between the water contents of the plant and the soil (Bergonci et al. 2000). In order to characterize the IRRI and WD treatments, the base water potential (predawn, $\Psi_{\text {pd }}$ ) of four fully expanded leaves was measured before dawn $(05: 00 \mathrm{~h})$ in a Scholander pressure chamber (Soil Moisture Equipment Corp., SEC-3015G2, Santa Barbara, CA, USA). The mean base water potential of the IRRI treatment was $-0.31 \mathrm{MPa}$, and the WD treatment was $-1.7 \mathrm{MPa}$.

Twelve hours before reaching the $55 \%$ FC of the soil, the plants were treated with $28 \mathrm{mM}$ trehalose (VetecSigma, St. Louis, MO, USA) or a mixture of trehalose derivatives (azide + tosyl) at $15 \mathrm{mM}$ and $13 \mathrm{mM}$, respectively (totaling $28 \mathrm{mM}$ ). The concentrations were based on the recommendations of Ali and Ashraf (2011). A second application was performed on day five of the water deficit period. The disaccharides were dissolved in water and ethylene glycol $(20 \%)$ and sprayed onto the shoots with a mechanical pressure sprayer (Guarani, PCP1P, 2-L capacity), at a concentration of $12.5 \mathrm{~mL}$ per plant (see also the corresponding video in supplement).

The experimental design was completely randomized (CRD), with four conditions: water deficit (WD), water deficit with trehalose (WD+TRE), water deficit with the mixture of trehalose derivatives (WD+TD), and irrigated (IRRI), each with five replications. The leaf gas exchange, relative chlorophyll (Chl) content, and Chl $a$ fluorescence were measured $24 \mathrm{~h}$ after spraying ( $1 \mathrm{~d}$ after water deficit, $1 \mathrm{dwd})$, at the end of the water stress period (12 d of water deficit, $12 \mathrm{dwd}$ ), and $12 \mathrm{~h}$ after water rehydration (Rehy), when the soil again reached $70 \%$ FC. No statistical comparisons were made between days, only between treatments. At the end of the experiment, the leaves were collected for anatomical analysis.

Leaf gas exchange and relative $\mathrm{Chl}$ content: Leaf gas exchange was measured with a portable photosynthesis system (IRGA, LI-6400 XT, Li-Cor, Lincoln, Nebraska, USA), and all measurements were performed in the morning (08:00-10:00 h) on the last fully expanded leaf. We evaluated the photosynthetic rate $\left(P_{\mathrm{N}}\right)$, stomatal conductance $\left(g_{\mathrm{s}}\right)$, transpiration $(E)$, and water-use efficiency (WUE). Measurements were taken on a $6-\mathrm{cm}^{2}$ leaf area, PPFD was $1,500 \mu \mathrm{mol} \mathrm{m} \mathrm{m}^{-2} \mathrm{~s}^{-1}$, with a blue-red LED light source (6400-02B LED), and leaf temperature was maintained at $30^{\circ} \mathrm{C}$. The relative $\mathrm{Chl}$ content was determined by a chlorophyll meter (Minolta SPAD-502, Konica Minolta, Chiyoda, Tokyo, Japan) as the mean of six readings per plant, in the middle of the last fully expanded leaf.

Chl fluorescence: A Mini-PAM modulated fluorometer (Heinz Walz, Effeltrich, Germany) was used to measure Chl $a$ fluorescence. After $30 \mathrm{~min}$ of dark adaptation, the minimum fluorescence $\left(\mathrm{F}_{0}\right)$ was measured with sufficiently low light to avoid photochemical reactions, and the maximum fluorescence $\left(\mathrm{F}_{\mathrm{m}}\right)$ was measured with a saturating light pulse $\left[7,000 \mu \mathrm{mol}\right.$ (photon) $\left.\mathrm{m}^{-2} \mathrm{~s}^{-1}\right]$ for $0.8 \mathrm{~s}$. In the dark-adapted samples, the maximum photosystem efficiency (PSII) was estimated as the $F_{v} / F_{m}$ ratio. Subsequently, the leaves were illuminated with actinic light $\left[1,500 \mu \mathrm{mol}\left(\right.\right.$ photon) $\left.\mathrm{m}^{-2} \mathrm{~s}^{-1}\right]$ to measure constant fluorescence $\left(\mathrm{F}_{\mathrm{s}}\right)$, and then another saturating light pulse was applied for $1 \mathrm{~s}$ to obtain the maximum fluorescence emitted by the leaves $\left(\mathrm{F}_{\mathrm{m}}{ }^{\prime}\right)$. The actinic light was removed and the leaves were irradiated with farred light to obtain light-adapted $\mathrm{F}_{0}\left(\mathrm{~F}_{0}{ }^{\prime}\right)$. Photochemical 
quenching was calculated as $\mathrm{q}_{\mathrm{P}}=\left(\mathrm{F}_{\mathrm{m}}{ }^{\prime}-\mathrm{F}_{\mathrm{s}}\right) /\left(\mathrm{F}_{\mathrm{m}}{ }^{\prime}-\mathrm{F}_{0}{ }^{\prime}\right)$, and nonphotochemical quenching was calculated as NPQ $=$ $\left(\mathrm{F}_{\mathrm{m}}-\mathrm{F}_{\mathrm{m}}{ }^{\prime}\right) / \mathrm{F}_{\mathrm{m}}{ }^{\prime}$. Other evaluated parameters included the electron transport rate, $\mathrm{ETR}=\left[\left(\mathrm{F}_{\mathrm{m}}{ }^{\prime}-\mathrm{F}_{\mathrm{s}} / \mathrm{F}_{\mathrm{m}}{ }^{\prime}\right) \times \mathrm{PPFD} \times\right.$ $0.5 \times 0.84$; the effective photochemical yield, $\mathrm{Y}_{\mathrm{II}}=\mathrm{F}_{\mathrm{m}}{ }^{\prime}-$ $\mathrm{F}_{\mathrm{s}} / \mathrm{F}_{\mathrm{m}}{ }^{\prime}=\Delta \mathrm{F} / \mathrm{F}_{\mathrm{m}}{ }^{\prime}$; quantum yield of nonregulated energy dissipation of PSII, $\mathrm{Y}_{\mathrm{NO}}=\mathrm{F}_{\mathrm{s}} / \mathrm{F}_{\mathrm{m}}$; and the quantum yield of regulated energy dissipation of PSII, $\mathrm{Y}_{\mathrm{NPQ}}=\mathrm{F}_{\mathrm{s}} / \mathrm{F}_{\mathrm{m}}{ }^{\prime}-\mathrm{F}_{\mathrm{s}} / \mathrm{F}_{\mathrm{m}}$ (van Kooten and Snel 1990).

Leaf anatomy analysis: The leaves were removed, washed with running water, and fixed in a $70 \%$ ethanol solution (Johansen 1940). Freehand cross sections were performed with a steel blade and support (Cecropia petiole). The sections were clarified with 5\% sodium hypochlorite for $8 \mathrm{~min}$, acetic acid for $5 \mathrm{~min}$, rehydrated for $15 \mathrm{~min}$, stained with Safrablau (Astra Blue and Safranin, at a ratio of 7.5:2.5), and mounted on $50 \%$ glycerine slides. The sections were photographed on an Axio Scope Al (Carl Zeiss, Oberkochen, Germany) light optical microscope fitted with a digital camera.

Photomicrographs were used to measure the leaf parameters, including the central rib thickness (LCT), central rib bundle distance (DSS), metaxylem diameter (XD), central rib fiber area (F), phloem area (P), limb thickness (LBT), epidermal thickness (ET), and cuticle thickness (CT). The epidermis and cuticle measurements were performed on the adaxial and abaxial faces.

For the analysis of the paradermal cuts, a thin layer of glue (Super Bonder ${ }^{\circledR}$, Loctite) was spread over the leaf. After drying, the glue layer, containing the impression of the leaf surface and slides, was removed and mounted for photography. This procedure was repeated for the adaxial and abaxial faces of the leaf. We measured the stomatal index (number of stomata/number of epidermal cells, SI), number of epidermal cells (EC), stomatal density (number of stomata $\left./ \mathrm{mm}^{2}, \mathrm{SD}\right)$, polar diameter of the stomata (PD), and stomatal functionality (polar diameter/equatorial diameter, SF).

Data analysis: Means \pm standard error (SE) were calculated for each parameter. Analysis of variance $(A N O V A)$ and the Scott-Knott's test, with a $0.05 \%$ significance $(P \leq 0.05)$ threshold, were used to compare the parameter means between treatments each day $(1 \mathrm{dwd}=$ one day after application, $12 \mathrm{dwd}=12$ days after application, and Rehy $=$ rehydration). All statistical analyses were conducted in the Sisvar software, version 4.3 (Universidade Federal de Lavras, Lavras, Brazil).

\section{Results}

Leaf gas exchange and relative $\mathrm{Chl}$ content: On the first day of stress $(1 \mathrm{dwd})$, the IRRI treatment had the highest photosynthetic rate $\left(P_{\mathrm{N}}\right)$, followed by the WD+TD treatment (Fig. $2 A$ ). After $12 \mathrm{dwd}$, the IRRI treatment had the highest $P_{\mathrm{N}}$, while the other treatments did not differ. Finally, after Rehy, the highest $P_{\mathrm{N}}$ was again observed in IRRI, followed by the WD+TRE and WD+TD treatments. The WD+TD group had a higher stomatal conductance $\left(g_{\mathrm{s}}\right)$ than that of the other stress treatments (WD and WD+TRE; Fig. $2 B$ ) at $1 \mathrm{dwd}$. At $12 \mathrm{dwd}$, the WD+TRE treatment had the lowest $g_{\mathrm{s}}$ value, and the IRRI group had the highest. However, when the plants were rehydrated, there was an increase in $g_{\mathrm{s}}$ in WD+TD and, to a lesser extent, in WD+TRE, compared to WD. None of the stress treatments had $g_{s}$ values equal to the irrigated plants after rehydration.

The transpiration rate $(E)$ after $1 \mathrm{dwd}$ showed similar patterns to $P_{\mathrm{N}}$ and $g_{\mathrm{s}}$ (Fig. 2C). After $12 \mathrm{dwd}$, the lowest $E$ were observed in the WD+TD and WD+TRE treatments. After rehydration, the lowest mean $E$ was observed in WD, followed by consistently increasing values in WD+TRE, WD+TD, and IRRI.

The water-use efficiency (WUE) was consistent after 1 dwd and Rehy; the WD+TD treatment had the lowest mean values (Fig. 2D). After $12 \mathrm{dwd}$, the lowest WUE was observed in the IRRI plants, and the other treatments did not differ.

The relative Chl content at $1 \mathrm{dwd}$ was the lowest in the WD treatment, while the rest of the treatments had similar values to the irrigated group (Fig. 2E). After $12 \mathrm{dwd}$ and after Rehy, the IRRI treatment had a higher relative Chl content than that of the other treatments, which did not differ.

Chl $\boldsymbol{a}$ fluorescence: The highest electron transport rate (ETR) at $1 \mathrm{dwd}$ was observed in IRRI, followed by plants in the WD+TD and WD+TRE treatments. The lowest ETR was observed in the WD treatment (Fig. 3A). After $12 \mathrm{dwd}$, ETR was the highest in IRRI, and the WD+TD treatment remained higher than that of the other WD treatments. After rehydration, the ETR of the WD+TRE and WD+TD treatments did not differ from the IRRI treatment but were higher than the WD group (Fig. 3A).

At $1 \mathrm{dwd}$, the highest PSII maximum efficiency $\left(\mathrm{F}_{\mathrm{v}} / \mathrm{F}_{\mathrm{m}}\right)$ values were observed in the IRRI and WD+TRE treatments. However, after $12 \mathrm{dwd}$, IRRI had the highest $\mathrm{F}_{\mathrm{v}} / \mathrm{F}_{\mathrm{m}}$, followed by WD+TD. The treatments did not differ after Rehy (Fig. 3B).

One day of stress resulted in higher photochemical quenching $\left(\mathrm{q}_{\mathrm{P}}\right)$ in the IRRI treatment, followed by WD+TD. The WD and WD+TRE groups had a $>50 \%$ reduction in $\mathrm{q}_{\mathrm{p}}$ when compared to the IRRI treatment. After $12 \mathrm{dwd}$ and Rehy, the WD+TRE and WD+TD plants had similar $\mathrm{q}_{\mathrm{P}}$ values to the IRRI plants (Fig. 3C).

The effective photochemical quantum yield of PSII ( $\mathrm{Y}_{\text {II }}$ was consistent at $1 \mathrm{dwd}$ and $12 \mathrm{dwd}$; the WD+TD treatment was superior to the other stress treatments but inferior to the IRRI treatment. After rehydration, the WD+TRE and WD+TD treatments had a higher $\mathrm{Y}_{\text {II }}$ than that of WD and IRRI (Fig. 3D).

After $1 \mathrm{dwd}$, the highest nonphotochemical quenching (NPQ) value was observed in the WD group and the lowest NPQ value was observed in the IRRI group (Fig. 4A). Both WD+TRE and WD+TD had lower NPQ values than that of WD. After $12 \mathrm{dwd}$, WD+TRE and IRRI had a lower NPQ value than that of the other treatments. There were no significant NPQ differences after rehydration.

The IRRI treatment had a higher quantum yield of 

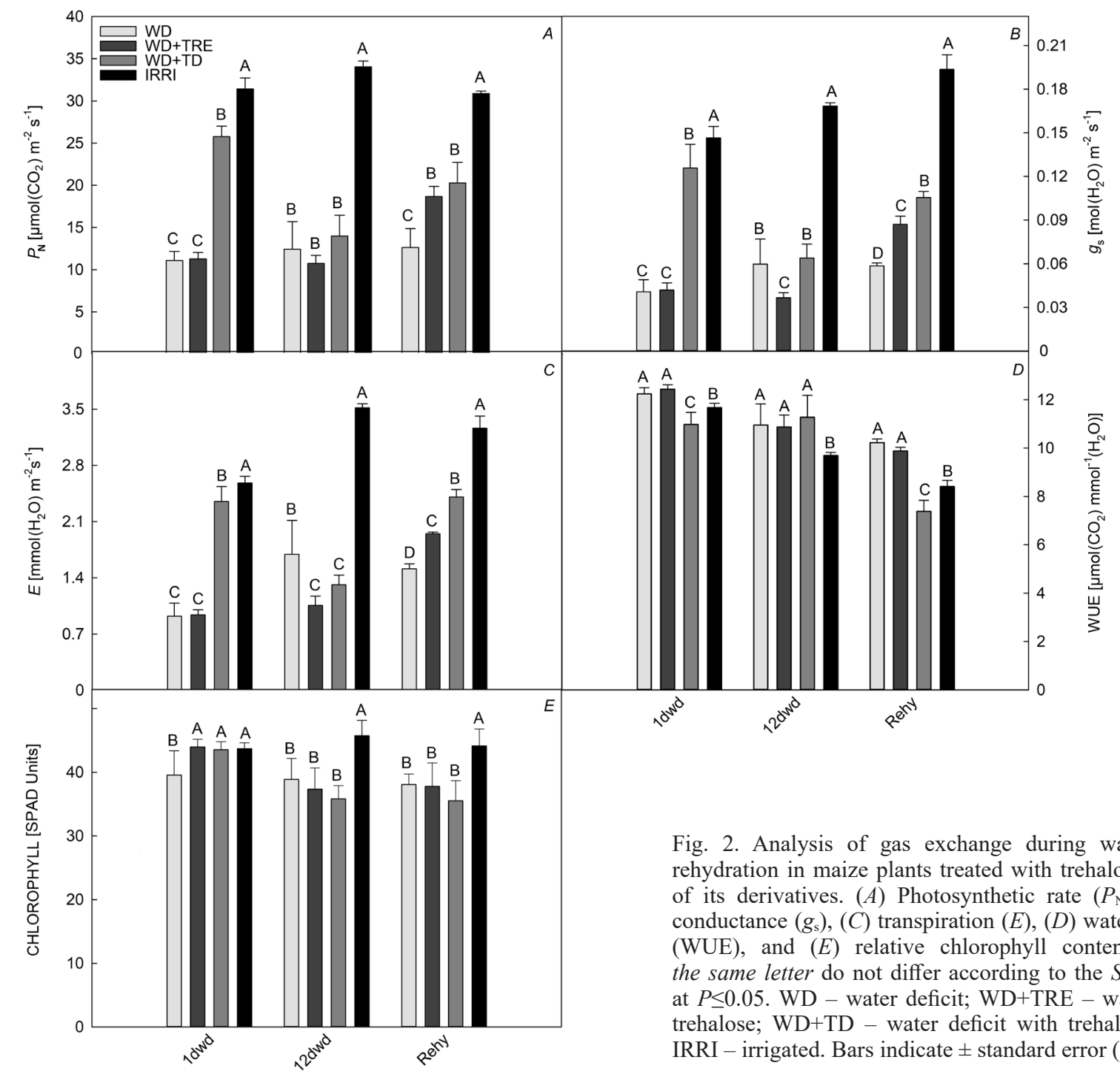

nonregulated energy dissipation of PSII $\left(\mathrm{Y}_{\mathrm{NO}}\right)$ than that in the other treatments after 1 dwd (Fig. $4 B$ ). However, at 12 dwd, only the WD+TD treatment differed; it had a lower $\mathrm{Y}_{\mathrm{NO}}$ value than that in the other groups. After Rehy, the highest $Y_{N O}$ value was observed in the WD treatment.

The IRRI treatment had the lowest quantum yield of regulated energy dissipation of PSII $\left(\mathrm{Y}_{\mathrm{NPQ}}\right)$ at $1 \mathrm{dwd}$ (Fig. 4C). After $12 \mathrm{dwd}$, the WD treatment had the lowest $\mathrm{Y}_{\mathrm{NPQ}}$ mean but, after Rehy, this value increased. At $12 \mathrm{dwd}$, $\mathrm{WD}+\mathrm{TRE}$ and $\mathrm{WD}+\mathrm{TD}$ had $\mathrm{Y}_{\mathrm{NPQ}}$ values similar to IRRI.

Leaf anatomy: The mean central rib thickness, distance between the central rib bundles, metaxylem diameter, and central rib fiber area of the cross-sectional parameters, did not differ between the treatments (data not shown). The WD and IRRI treatments had a higher central rib phloem area $(\mathrm{P})$ than that of the WD+TD and WD+TRE groups (Fig. 5A). The highest limb thickness (LBT) was observed in WD+TRE, followed by WD, and LBT was the lowest in WD+TD and IRRI (Fig. 5B). The adaxial epidermis thickness (ET) did not vary among the treatment groups,

Fig. 2. Analysis of gas exchange during water deficit and rehydration in maize plants treated with trehalose or a mixture of its derivatives. $(A)$ Photosynthetic rate $\left(P_{\mathrm{N}}\right),(B)$ stomatal conductance $\left(g_{\mathrm{s}}\right),(C)$ transpiration $(E),(D)$ water-use efficiency (WUE), and $(E)$ relative chlorophyll content. Means with the same letter do not differ according to the Scott-Knott's test at $P \leq 0.05$. WD - water deficit; WD+TRE - water deficit with trehalose; $\mathrm{WD}+\mathrm{TD}-$ water deficit with trehalose derivatives; IRRI - irrigated. Bars indicate \pm standard error (SE) $(n=5)$.

but the abaxial ET was the highest in WD+TD (Fig. 5C). WD+TRE and IRRI had the highest adaxial cuticle thickness (CT), while, on the abaxial face, WD+TD had the lowest CT (Fig. 5D).

Analyses of the paradermal sections revealed no significant differences in epidermal cell number, polar diameter, or stomatal index. The adaxial stomatal density (SD) was the same for all treatments, but on the abaxial face, WD+TD had a higher SD value (Figs. 6A, 7). The WD+TRE and WD treatments had higher adaxial stomatal functionality (SF), followed by IRRI, while the other treatments did not differ (Fig. 6B). There were no statistical differences between the abaxial SF means.

\section{Discussion}

Stomatal closure is a plant's first line of defense against water deficit, and it may be accompanied by reduced carbon assimilation, which compromises the photosynthetic process $\left(P_{\mathrm{N}}\right)$ (Chaves 1991, Tounekti et al. 2018). In maize plants, water deficits cause two types of photosynthetic 


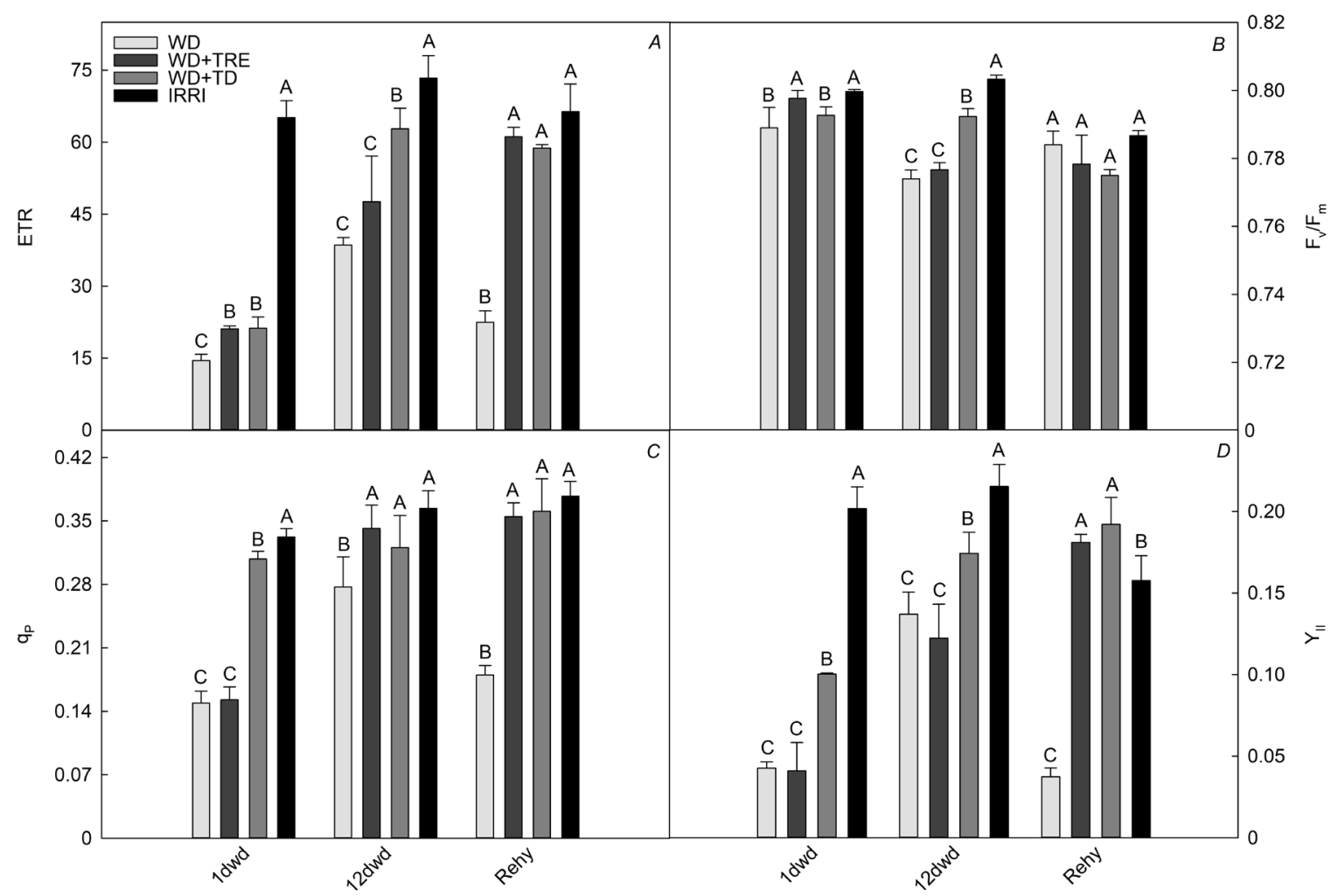

Fig. 3. Analysis of chlorophyll $a$ fluorescence during water deficit and rehydration in maize plants treated with trehalose or a mixture of its derivatives. $(A)$ Electron transport rate $(\mathrm{ETR}),(B)$ maximum efficiency of PSII $\left(\mathrm{F}_{\mathrm{v}} / \mathrm{F}_{\mathrm{m}}\right),(C)$ photochemical quenching $\left(\mathrm{q}_{\mathrm{P}}\right)$, and $(D)$ effective photochemical quantum production of PSII $\left(\mathrm{Y}_{\mathrm{II}}\right)$. Means with the same letter do not differ according to the Scott-Knott's test at $P \leq 0.05$. WD - water deficit; WD+TRE - water deficit with trehalose; WD+TD - water deficit with trehalose derivatives; IRRI irrigated. Bars indicate \pm standard error (SE) $(n=5)$.

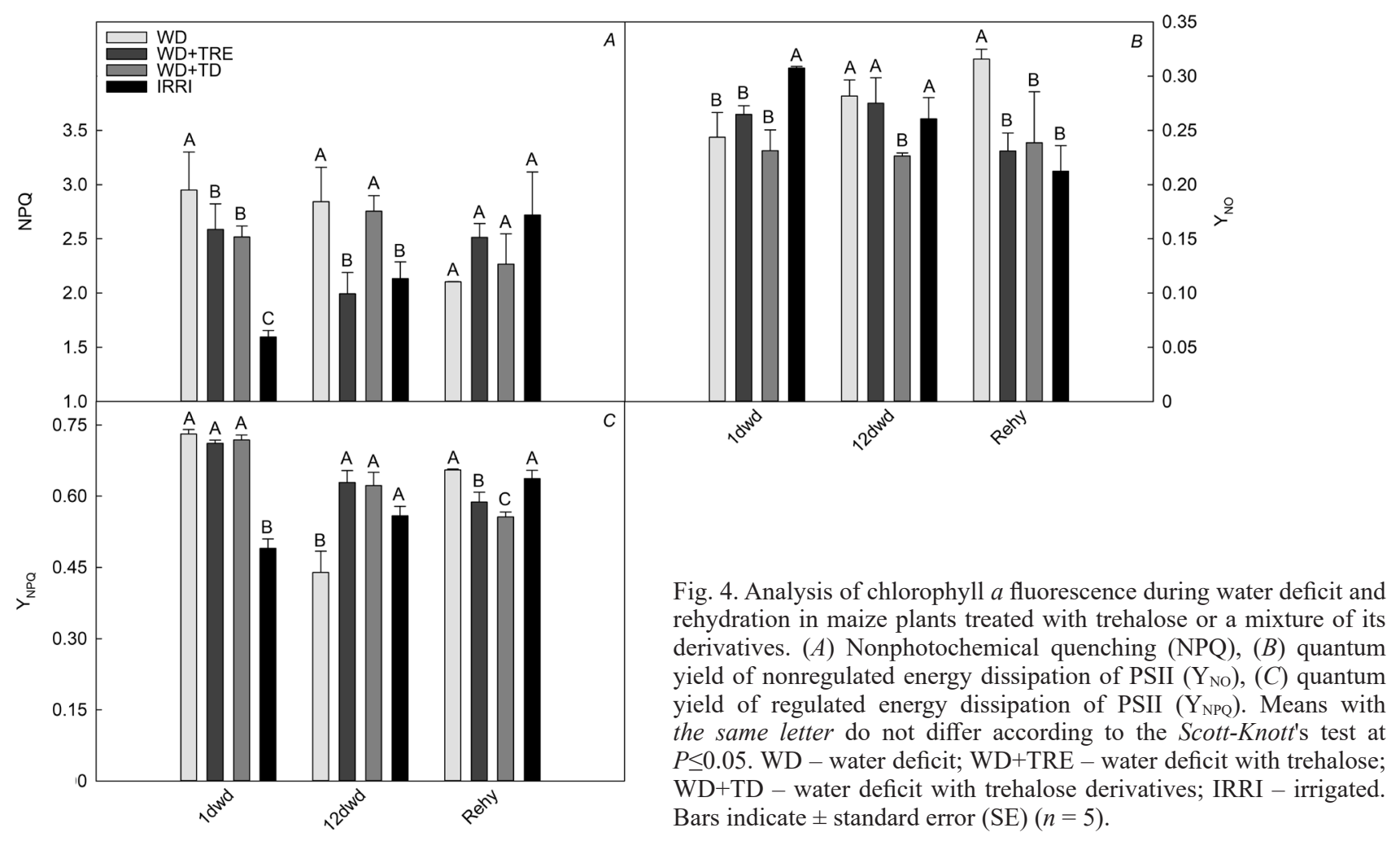




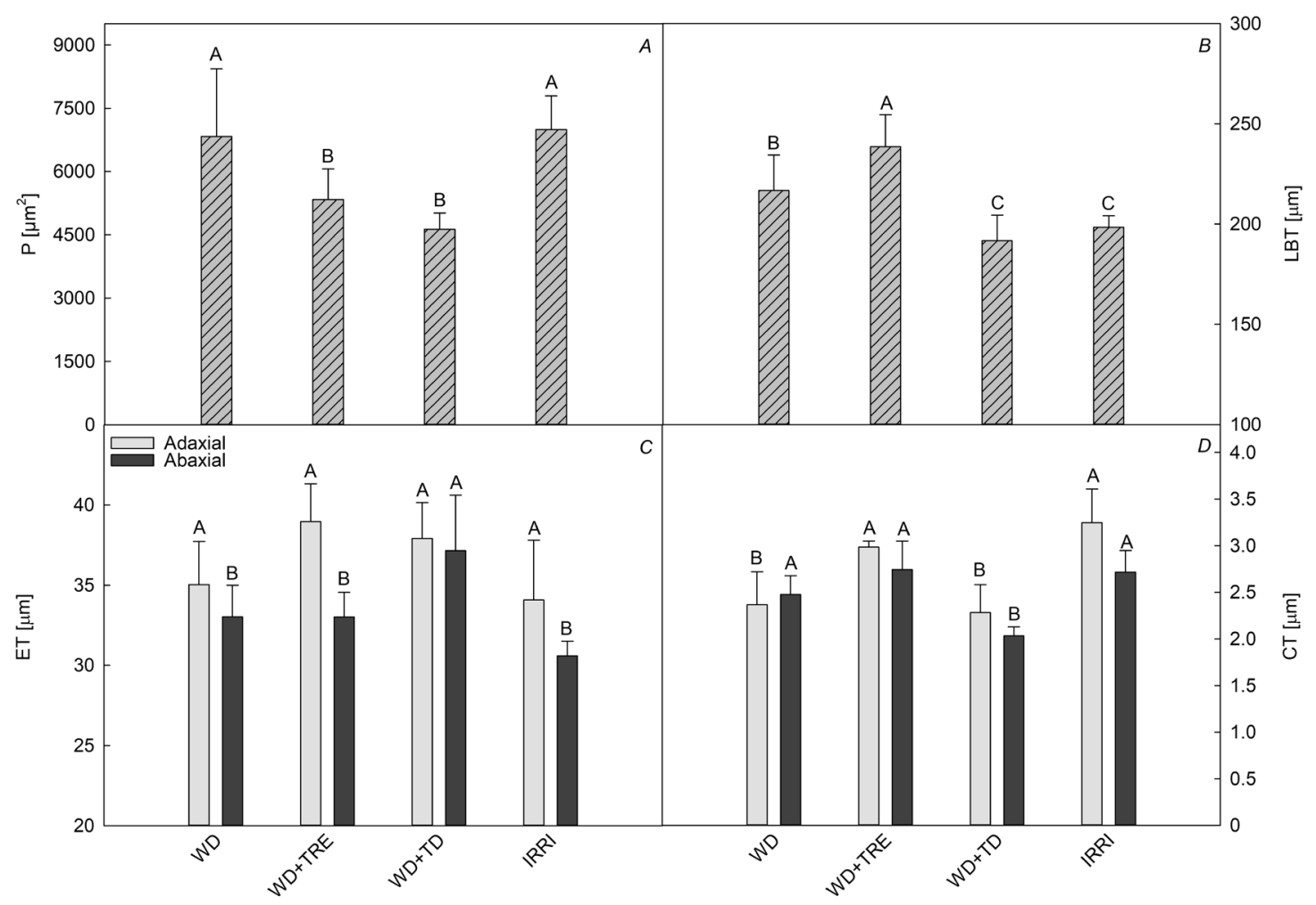

Fig. 5. Analysis of maize leaf cross sections treated with trehalose or a mixture of its derivatives after 12 days of water deficit stress. $(A)$ Phloem area of the central rib $(\mathrm{P}),(B)$ limb thickness (LBT), $(C)$ thickness of adaxial and abaxial epidermis $(\mathrm{ET})$, and $(D)$ thickness of the adaxial and abaxial cuticles. Means with the same letter do not differ according to the Scott-Knott's test at $P \leq 0.05$. WD - water deficit; WD+TRE - water deficit with trehalose; WD+TD - water deficit with trehalose derivatives; IRRI - irrigated. Bars indicate \pm standard error (SE) $(n=5)$.

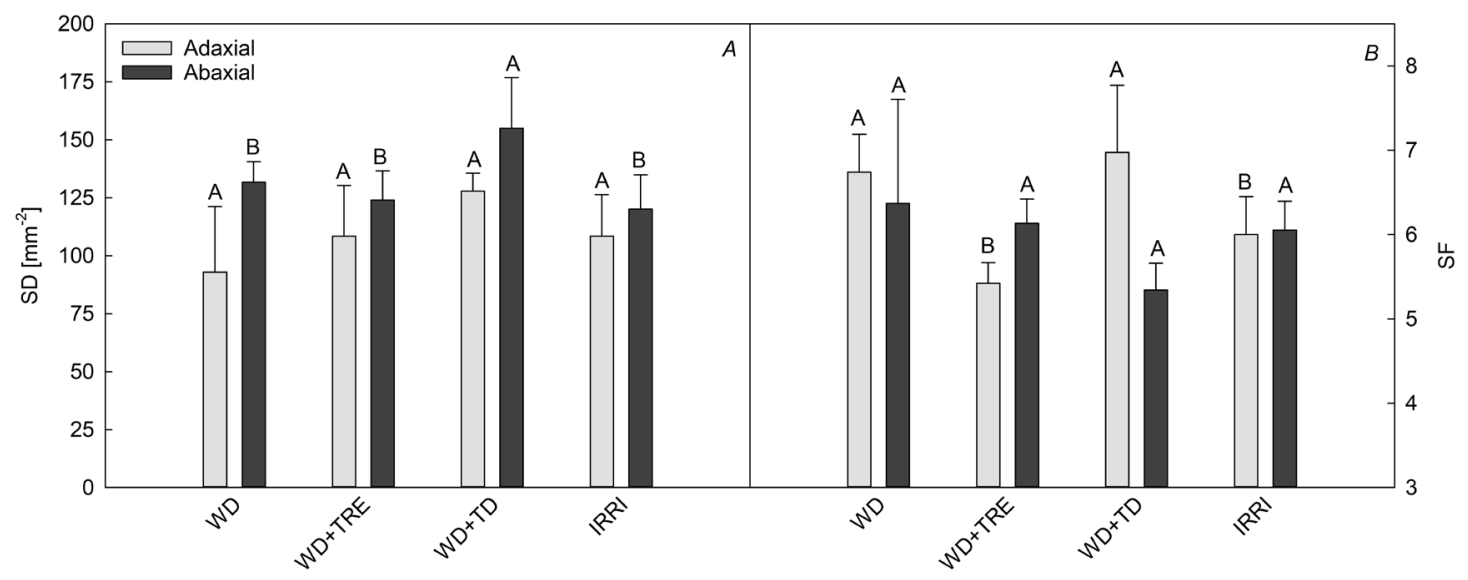

Fig. 6. Analysis of maize leaf paradermal sections treated with trehalose or a mixture of its derivatives after $12 \mathrm{~d}$ of water deficit stress. $(A)$ Stomatal density (SD) and (B) stomatal functionality (SF). Means with the same letter do not differ according to the Scott-Knott's test at $P \leq 0.05$. WD - water deficit; WD+TRE - water deficit with trehalose; WD+TD - water deficit with trehalose derivatives; IRRI irrigated. Bars indicate \pm standard error $(\mathrm{SE})(n=5)$.

limitations: stomatal, related to stomatal gas conductance, and nonstomatal, such as increased Chl fluorescence or an impaired photosynthetic apparatus (Parry et al. 2007, Chatterjee and Basu 2011, Perdomo et al. 2017).

The application of trehalose to the leaves of plants increases $P_{\mathrm{N}}$ under water deficit conditions (Ali and
Ashraf 2011). In our study, this increase was observed after rehydration. The trehalose derivatives mixture, on the other hand, mitigated $P_{\mathrm{N}}$ reduction at $1 \mathrm{dwd}$ and after rehydration, suggesting that the derivatives better protect the photosynthetic apparatus. Higher $P_{\mathrm{N}}$ due to trehalose and derivatives application may be related to higher $\mathrm{CO}_{2}$ 


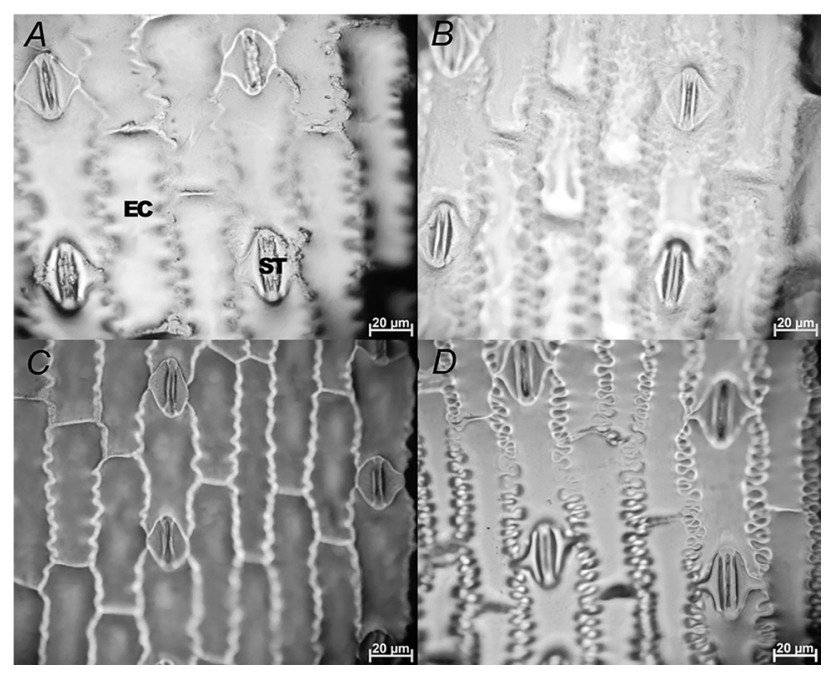

Fig. 7. Photomicrograph of the paradermal sections on the abaxial face of maize hybrid BRS 1030, where it is possible to visualize stomata and epidermal cells. $(A)$ Water deficit - WD, $(B)$ water deficit with trehalose - WD+TRE, $(C)$ water deficit with trehalose derivatives $-\mathrm{WD}+\mathrm{TD}$, and $(D)$ irrigated - IRRI. ST - stomata, EC - epidermal cells. The bar corresponds to $20 \mu \mathrm{m}$.

assimilation, as higher $P_{\mathrm{N}}$ was accompanied by higher $g_{\text {s }}$ and $E$.

The trehalose derivatives also increased stomatal density - the mean values were higher than that in the trehalose treatment. The greater number of stomata per unit area and the increase in $g_{\mathrm{s}}$ probably led to a $P_{\mathrm{N}}$ increase in the derivatives mixture treatment, since higher $g_{\mathrm{s}}$ results in greater carbon assimilation for photosynthesis (Farquhar and Sharkey 1982, Hubbard et al. 2001). Thus, the trehalose derivatives mixture may also alleviate/ mitigate stomatal limitations in maize plants under water deficit.

Stomatal closure results in a reduction in $g_{s}$, which is the most sensitive indicator of soil water availability (Miyashita et al. 2005, Yan et al. 2016). Reduced $g_{\mathrm{s}}$ in plants under water deficit is associated with reduced $E$, which prevents plant desiccation ( $\mathrm{Gu}$ et al. 2012). However, $g_{\mathrm{s}}$ reductions also decrease water loss by the leaf(Urban et al. 2017), limit $\mathrm{CO}_{2}$ input into the mesophyll, and limit $\mathrm{CO}_{2}$ assimilation via enzyme activity impairment (Perdomo et al. 2017, Mohammadi 2018). At the beginning of the stress period $(1 \mathrm{dwd})$ and after rehydration, $g_{\mathrm{s}}$ increased in the maize plants treated with trehalose, and $P_{\mathrm{N}}$ increased in the plants treated with the trehalose derivatives mixture. Some plant species respond to water deficit conditions by fast stomata opening to cool the leaves and for faster photosynthesis due to a better water status in the leaves (Souza et al. 2013, dos Reis et al. 2019). Our results are consistent with Ali and Ashraf (2011); trehalose and the trehalose derivatives induce similar responses (i.e., opening stomata) during the initial stress and rehydration periods.

The role of trehalose in the maintenance of plant water status is related to two aspects of metabolism osmotically active solute and antioxidative function. The trehalose-driven accumulation of compatible solutes may lead to osmotic modification and better leaf water status (Fang and Xiong 2015, Anjum et al. 2017). Trehalose stimulates the antioxidant system of plants (Mostofa et al. 2015, Kosar et al. 2019, Zhao et al. 2019), reducing ROS production (Zhao et al. 2019), and functions as an antioxidant, neutralizing ROS generated by water deficit stress (Kosar et al. 2019). Trehalose has also been shown to promote higher antioxidant activity and lower cell damage in other stress conditions (Mostofa et al. 2015, Shafiq et al. 2015).

After $12 \mathrm{~d}$ of water deficit, neither trehalose nor the trehalose derivatives influenced $P_{\mathrm{N}}$. This was despite decreased $g_{\mathrm{s}}$ (WD+TRE) and $E$ (WD+TRE and WD+TD) at $12 \mathrm{dwd} ; P_{\mathrm{N}}$ for all of the treatment groups was similar to the WD plants. This may be due to the increased capacity of the plants to save water without compromising their photosynthetic rates. Trehalose and its derivatives prevent impairment of the photosynthetic apparatus, which may have mitigated the nonstomatal limitations of photosynthesis under water deficit conditions.

WUE and the relative $\mathrm{Chl}$ content (SPAD) are indicators of plant tolerance to water stress (Silva et al. 2007, Arunyanark et al. 2008, Songsri et al. 2009). Interestingly, the WD+TRE treatment group had a higher WUE than that in the IRRI group (in all analyzed periods). The trehalose derivatives mixture reduced the mean WUE values at $1 \mathrm{dwd}$ and during rehydration. This suggests that the derivatives mixture efficiently minimized the effects of the water deficit, allowing a higher water status that maintains stomatal opening and eliminates the need for high WUE values to ensure plant survival. Thus, the trehalose derivatives act by allowing higher water use (WU), not higher water-use efficiency (WUE). This increases the possibility of wasting water in the maize plants that received the trehalose derivatives and may be related to better osmoprotection and osmoregulation from the sugars (Ali and Ashraf 2011, Fang and Xiong 2015, Anjum et al. 2017).

Water deficits may increase, decrease, or not influence the Chl content (SPAD) (Puangbut et al. 2017, Dordas et al. 2018, Song et al. 2018). Trehalose is known to increase the Chl content under stress, as observed at $1 \mathrm{dwd}$ in the WD+TRE and WD+TD treatments. This is likely due to trehalose maintaining Chl stability and the osmotic potential balance of the chloroplast (Akram et al. 2015, Tarek et al. 2017, Kosar et al. 2019).

Water deficit-stressed plants with reduced $g_{\text {s }}$ values also have low ETR values (Flexas et al. 2002, Naidoo and Naidoo 2018). During water deficit, the ETR of maize leaves treated with the trehalose derivatives mixture followed the patterns observed for $g_{\mathrm{s}}$ and $P_{\mathrm{N}}$. This suggests that electron transport and stomatal behavior work together to supply $\mathrm{CO}_{2}$ and water for plant metabolism (Gleason et al. 2017) and that the derivatives enhance the photosynthetic process. Under stress conditions, higher trehalose production is associated with higher ETR in plants (Garg et al. 2002), but no studies have investigated 
how the application of trehalose or its derivatives influences this relationship. Maize plants tolerant to water deficits have a higher ETR under stress (Souza et al. 2013), thus, the trehalose derivatives may mitigate stress by increasing ETR at $12 \mathrm{dwd}$.

The $F_{v} / F_{m}$ ratio can be used to assess damage to the photosynthetic apparatus caused by stress (Souza et al. 2013). The trehalose derivatives mixture was effective at mitigating photoinhibition due to the water deficit at $12 \mathrm{dwd}$. In heat-stressed wheat, trehalose is also related to better protein $\mathrm{D} 1$ protection by relieving photoinhibition (Luo et al. 2018). In this study, both disaccharide treatments resulted in a more efficient photosynthetic apparatus at the beginning and end of the stress period than the nonsprayed treatments. Also, the trehalose derivatives mitigated the effects of decreased $Y_{\text {II }}$. The mitigating effects of reduced NPQ and increased $\mathrm{q}_{\mathrm{P}}$ were also documented by Gao et al. (2013) and Pilon-Smits et al. (1998) after trehalose treatment in other plant species.

The ability of the trehalose derivatives to dissipate excess electrons and protect the photosystems is supported by our analyses of the NPQ partition; after $12 \mathrm{~d}$ of stress, these molecules resulted in the maintenance of $\mathrm{Y}_{\mathrm{NPQ}}$ and a decrease in $\mathrm{Y}_{\mathrm{NO}}$. $\mathrm{Y}_{\mathrm{NO}}$ represents the passive nonphotochemical energy dissipated in unregulated forms due to the closure of PSII reaction centers (e.g., energy that is channeled to ROS). On the other hand, $\mathrm{Y}_{\mathrm{NPQ}}$ represents the heat-dissipated energy of the regulated NPQ mechanisms (i.e., the xanthophyll cycle or heat release) (Cousins et al. 2002, Klughammer and Schreiber 2008). The induction of the trehalose derivatives results in energy release for enzymatic reactions and heat, which avoids ROS generation (dos Reis et al. 2019) and attenuates the pressure on the reaction centers (Khan et al. 2017).

A water deficit increases the phloem area of the leaf central rib (F) but, in some maize cultivars, water scarcity did not influence the leaf vascular bundle size (Guha et al. 2018, Hoque et al. 2018). This is consistent with our results. An increased phloem area is indicative of more vessels that carry sugars to the developing regions (e.g., new leaves and roots) or promotes osmoregulation (Das et al. 2015). In this study, the applied sugar treatments decreased the phloem area.

The trehalose derivatives mixture increased in the epidermis thickness (ET) of the abaxial face, which was more efficient at preventing water loss on the leaf surface (Nawazish et al. 2006) than trehalose alone. In this study, the LBT of the WD+TRE treatment was higher than the IRRI group, but the ET and CT values of the two treatments were equal. Interestingly, the mixture of trehalose derivatives led to thinner maize leaves (LBT) with the lower cuticle thickness (CT), which are the anatomical characteristics of plant leaves under more favorable humidity conditions. Thus, the derivatives mixture relieved the adverse effects of water deficits in plants that are not adapted to dry environments.

A greater number of stomata per area (i.e., stomatal density, SD) may favor leaf gas exchange (Souza et al. 2010). Leaf SD increases under moderate water deficits but decreases with severe stress (Xu and Zhou 2008).
A lack of water causes the plant to regulate stomatal development in new leaves, reducing SD to decrease water loss (Hamanishi et al. 2012, Bi et al. 2017). However, the derivatives mixture increased SD (Fig. 7), favoring greater $P_{\mathrm{N}}, g_{\mathrm{s}}$, and $E$. Stomatal functionality (SF) is linked to stomatal size, and the stomatal area opening and water-saving can improve the water status of plants (Zhao et al. 2015). However, SF did not explain the WUE patterns observed in the WD+TRE and WD+TD plants in this study.

Conclusion: Trehalose triggers physiological and anatomical modifications to save water, but the mixture of derivatives triggers responses to maintain high photosynthetic activity, despite greater water loss. Thus, the azide and tosylated trehalose derivatives mixture mitigates the effects of water deficits in maize plants and may contribute to future biostimulant research.

\section{References}

Adiaha M.S., Agba O.A., Attoe E.E. et al.: Effect of maize (Zea mays L.) on human development and the future of man-maize survival: A review. - World Sci. News 59: 52-62, 2016.

Akram N.A., Noreen S., Noreen T., Ashraf M.: Exogenous application of trehalose alters growth, physiology and nutrient composition in radish (Raphanus sativus L.) plants under water-deficit conditions. - Braz. J. Bot. 38: 431-439, 2015.

Ali Q., Ashraf M.: Induction of drought tolerance in maize (Zea mays L.) due to exogenous application of trehalose: Growth, photosynthesis, water relations and oxidative defence mechanism. - J. Agron. Crop Sci. 197: 258-271, 2011.

Anjum S.A., Ashraf U., Tanveer M. et al.: Drought induced changes in growth, osmolyte accumulation and antioxidant metabolism of three maize hybrids. - Front. Plant Sci. 8: 69, 2017.

Arunyanark A., Jogloy S., Akkasaeng C. et al.: Chlorophyll stability is an indicator of drought tolerance in peanut. J. Agron. Crop Sci. 194: 113-125, 2008.

Bergonci J.I., Bergamaschi H., Berlato M.A. et al.: [Leaf water potential as an indicator of water deficit in maize.] - Pesqui. Agropecu. Bras. 35: 1531-1540, 2000. [In Portuguese]

Bi H., Kovalchuk N., Langridge P. et al.: The impact of drought on wheat leaf cuticle properties. - BMC Plant Biol. 17: 85, 2017.

Bosch S., De Beaurepaire L., Allard M. et al.: Trehalose prevents aggregation of exosomes and cryodamage. - Sci. Rep.-UK 6: 36162, 2016.

Calvo P., Nelson L., Kloepper J.W.: Agricultural uses of plant biostimulants. - Plant Soil 383: 3-41, 2014.

Chatterjee A., Basu A.: Rubisco: Limitations and re-engineering for a better enzyme. - Int. Res. J. Plant Sci. 2: 022-024, 2011.

Chaves M.M.: Effects of water deficits on carbon assimilation. J. Exp. Bot. 42: 1-16, 1991.

Cousins A.B., Adam N.R., Wall G.W. et al.: Photosystem II energy use, non-photochemical quenching and the xanthophyll cycle in Sorghum bicolor grown under drought and free-air $\mathrm{CO}_{2}$ enrichment (FACE) conditions. - Plant Cell Environ. 25: 1551-1559, 2002.

Daina A., Michielin O., Zoete V.: SwissADME: A free web tool to evaluate pharmacokinetics, drug-likeness and medicinal chemistry friendliness of small molecules. - Sci. Rep.-UK 7: 42717, 2017.

Das R., Bhagawati K., Boro A. et al.: Relative performance 
of plant cultivars under respective water deficit adaptation strategies: A case study. - Curr. World Environ. 10: 683-690, 2015.

de Souza T.B., Raimundo P.O.B., Andrade S.F. et al.: Synthesis and antimicrobial activity of 6-triazolo-6-deoxy eugenol glucosides. - Carbohydr. Res. 410: 1-8, 2015.

de Souza T.C., de Castro E.M., César Magalhães P. et al.: Morphophysiology, morphoanatomy, and grain yield under field conditions for two maize hybrids with contrasting response to drought stress. - Acta Physiol. Plant. 35: 32013211, 2013.

Dordas C.A., Papathanasiou F., Lithourgidis A. et al.: Evaluation of physiological characteristics as selection criteria for drought tolerance in maize inbred lines and their hybrids. Maydica 63: M13, 2018.

dos Reis C.O., Magalhães P.C., Avila R.G. et al.: Action of $\mathrm{N}$-succinyl and $\mathrm{N}, \mathrm{O}$-dicarboxymethyl chitosan derivatives on chlorophyll photosynthesis and fluorescence in droughtsensitive maize. - J. Plant Growth Regul. 38: 619-630, 2019.

du Jardin P.: Plant biostimulants: Definition, concept, main categories and regulation. - Sci. Hortic.-Amsterdam 196: 3-14, 2015.

Efeoğlu B., Ekmekçi Y., Çiçek N.: Physiological responses of three maize cultivars to drought stress and recovery. $-\mathrm{S}$. Afr. J. Bot. 75: 34-42, 2009.

Fang Y., Xiong L.: General mechanisms of drought response and their application in drought resistance improvement in plants. - Cell. Mol. Life Sci. 72: 673-689, 2015.

FAO, IFAD, UNICEF et al.: The State of Food Security and Nutrition in the World 2018. Building Climate Resilience for Food Security and Nutrition. Pp. 222. FAO, Rome 2018.

Farquhar G.D., Sharkey T.D.: Stomatal conductance and photosynthesis. - Ann. Rev. Plant Physio. 33: 317-345, 1982.

Flexas J., Bota J., Escalona J.M. et al.: Effects of drought on photosynthesis in grapevines under field conditions: an evaluation of stomatal and mesophyll limitations. - Funct. Plant Biol. 29: 461-471, 2002.

Gao J., Wang N., Xu S.S. et al.: Exogenous application of trehalose induced $\mathrm{H}_{2} \mathrm{O}_{2}$ production and stomatal closure in Vicia faba. - Biol. Plantarum 57: 380-384, 2013.

Garg A.K., Kim J., Owens T.G. et al.: Trehalose accumulation in rice plants confers high tolerance levels to different abiotic stresses. - P. Natl. Acad. Sci. USA. 99: 15898-15903, 2002.

Gleason S.M., Wiggans D.R., Bliss C.A. et al.: Coordinated decline in photosynthesis and hydraulic conductance during drought stress in Zea mays. - Flora 227: 1-9, 2017.

$\mathrm{Gu}$ J., Yin X., Stomph T.-J. et al.: Physiological basis of genetic variation in leaf photosynthesis among rice (Oryza sativa L.) introgression lines under drought and well-watered conditions. - J. Exp. Bot. 63: 5137-5153, 2012.

Guha A., Chhajed S.S., Choudhary S. et al.: Hydraulic anatomy affects genotypic variation in plant water use and shows differential organ specific plasticity to drought in Sorghum bicolor. - Environ. Exp. Bot. 156: 25-37, 2018.

Hamanishi E.T., Thomas B.R., Campbell M.M.: Drought induces alterations in the stomatal development program in Populus. J. Exp. Bot. 63: 4959-4971, 2012.

Hazrati S., Tahmasebi-Sarvestani Z., Modarres-Sanavy S.A.M. et al:: Effects of water stress and light intensity on chlorophyll fluorescence parameters and pigments of Aloe vera L. - Plant Physiol. Bioch. 106: 141-148, 2016.

Hoque M.I.U., Uddin M.N., Fakir M.S.A. et al.: Drought and salinity affect leaf and root anatomical structures in three maize genotypes. - J. Bangladesh Agric. Univ. 16: 47-55, 2018.

Hsieh S.-W., Lee M.-R., Tsai C.-W. et al.: Enzymatic synthesis, purification and identification of bioactive trehalose ester derivatives for health applications. - Food Bioprod. Proc. 95: 163-172, 2015.

Hubbard R.M., Ryan M.G., Stiller V., Sperry J.S.: Stomatal conductance and photosynthesis vary linearly with plant hydraulic conductance in ponderosa pine. - Plant. Cell Environ. 24: 113-121, 2001.

Jabeen F., Shahbaz M., Ashraf M.: Discriminating some prospective cultivars of maize (Zea mays L.) for drought tolerance using gas exchange characteristics and proline contents as physiological markers. - Pak. J. Bot. 40: 23292343, 2008.

Johansen D.A.: Plant Microtechnique. Pp. 523. McGraw-Hill Publishing Company, London 1940.

Kałużewicz A., Krzesinski W., Spizewski T., Zaworska A.: Effect of biostimulants on several physiological characteristics and chlorophyll content in broccoli under drought stress and re-watering. - Not. Bot. Horti. Agrobo. 45: 197-202, 2017.

Khan F., Upreti P., Singh R. et al.: Physiological performance of two contrasting rice varieties under water stress. - Physiol. Mol. Biol. Pla. 23: 85-97, 2017.

Klughammer C., Schreiber U.: Complementary PS II quantum yields calculated from simple fluorescence parameters measured by PAM fluorometry and the Saturation Pulse method. - PAM Appl. Notes 1: 27-35, 2008.

Kosar F., Akram N.A., Sadiq M. et al.: Trehalose: A key organic osmolyte effectively involved in plant abiotic stress tolerance.J. Plant Growth Regul. 38: 606-618, 2019.

Larkins B.A.: Maize Kernel Development. Pp. 252. CABI, Wallingford 2017.

Lawson T., Terashima I., Fujita T., Wang Y.: Coordination between photosynthesis and stomatal behavior. - In: Adams III W.W., Terashima I. (ed.): The Leaf: A Platform for Performing Photosynthesis. Pp. 141-161. Springer, Cham 2018.

Lawson T., Vialet-Chabrand S.: Speedy stomata, photosynthesis and plant water use efficiency. - New Phytol. 221: 93-98, 2019.

Liu M., Qi M., Zhang Z. et al.: Response of photosynthesis and chlorophyll fluorescence to drought stress in two maize cultivars. - Afr. J. Agr. Res. 7: 4751-4760, 2012.

Luo Y., Wang W., Fan Y.Z. et al.: Exogenously-supplied trehalose provides better protection for D1 protein in winter wheat under heat stress. - Russ. J. Plant Physl+ 65: 115-122, 2018.

Magalhães P.C., Durães F.O.M.: [Maize Production Physiology.] Pp. 1-10. Embrapa Maize and Sorghum, Sete Lagoas 2006. [In Portuguese]

Mathobo R., Marais D., Steyn J.M.: The effect of drought stress on yield, leaf gaseous exchange and chlorophyll fluorescence of dry beans (Phaseolus vulgaris L.). - Agr. Water Manage. 180: 118-125, 2017.

Menger F.M., Mbadugha B.N.A.: Gemini surfactants with a disaccharide spacer. - J. Am. Chem. Soc. 123: 875-885, 2001.

Miyashita K., Tanakamaru S., Maitani T., Kimura K.: Recovery responses of photosynthesis, transpiration, and stomatal conductance in kidney bean following drought stress. Environ. Exp. Bot. 53: 205-214, 2005.

Mnif I., Ghribi D.: Glycolipid biosurfactants: main properties and potential applications in agriculture and food industry. J. Sci. Food Agr. 96: 4310-4320, 2016.

Mohammadi R.: Breeding for increased drought tolerance in wheat: a review. - Crop Pasture Sci. 69: 223-241, 2018.

Mostofa M.G., Hossain M.A., Fujita M.: Trehalose pretreatment induces salt tolerance in rice (Oryza sativa L.) seedlings: oxidative damage and co-induction of antioxidant defense and glyoxalase systems. - Protoplasma 252: 461-475, 2015.

Naidoo G., Naidoo K.K.: Drought stress effects on gas exchange 
and water relations of the invasive weed Chromolaena odorata. - Flora 248: 1-9, 2018.

Nawazish S., Hameed M., Naurin S.: Leaf anatomical adaptations of Cenchrus ciliaris L., from the Salt Range, Pakistan against drought stress. - Pak. J. Bot. 38: 1723-1730, 2006.

Oliveri V., Bellia F., Grasso G.I. et al.: Trehalose-8hydroxyquinoline conjugates as antioxidant modulators of $\mathrm{A} \beta$ aggregation. - RSC Adv. 6: 47229-47236, 2016.

Parry M.A.J., Madgwick P.J., Carvalho J.F.C., Andralojc P.J.: Prospects for increasing photosynthesis by overcoming the limitations of Rubisco. - J. Agr. Sci. 145: 31-43, 2007.

Perdomo J.A., Capó-Bauçà S., Carmo-Silva E., Galmés J.: Rubisco and rubisco activase play an important role in the biochemical limitations of photosynthesis in rice, wheat, and maize under high temperature and water deficit. - Front. Plant Sci. 8: 490, 2017.

Pilon-Smits E.A.H., Terry N., Sears T. et al.: Trehalose-producing transgenic tobacco plants show improved growth performance under drought stress. - J. Plant Physiol. 152: 525-532, 1998.

Puangbut D., Jogloy S., Vorasoot N.: Association of photosynthetic traits with water use efficiency and SPAD chlorophyll meter reading of Jerusalem artichoke under drought conditions. Agr. Water Manage. 188: 29-35, 2017.

Rabêlo V.M., Magalhães P.C., Bressanin L.A. et al.: The foliar application of a mixture of semisynthetic chitosan derivatives induces tolerance to water deficit in maize, improving the antioxidant system and increasing photosynthesis and grain yield. - Sci. Rep.-UK 9: 8164, 2019.

Raij B., Andrade J., Cantarella H. et al.: [Chemical analysis to assess the fertility of tropical soils.] Pp. 285. Instituto Agronômico, Campinas 2001. [In Portuguese]

Riboldi L.B., Oliveira R.F., Angelocci L.R.: Leaf turgor pressure in maize plants under water stress. - Aust. J. Crop Sci. 10: 878-886, 2016.

Santos H.G. dos, Jacomine P.K.T., Anjos L.H.C. dos et al.: Brazilian Soil Classification System. Pp. 210. Embrapa, Brasilia 2018.

Shafiq S., Akram N.A., Ashraf M.: Does exogenously-applied trehalose alter oxidative defense system in the edible part of radish (Raphanus sativus L.) under water-deficit conditions? Sci. Hortic.-Amsterdam 185: 68-75, 2015.

Silva M.D.A., Jifon J.L., Silva J.A.G. et al.: Use of physiological parameters as fast tools to screen for drought tolerance in sugarcane. - Braz. J. Plant Physiol. 19: 193-201, 2007.

Song H., Li Y., Zhou L. et al.: Maize leaf functional responses to drought episode and rewatering. - Agr. Forest Meteorol. 249: 57-70, 2018.

Songsri P., Jogloy S., Holbrook C.C. et al.: Association of root, specific leaf area and SPAD chlorophyll meter reading to water use efficiency of peanut under different available soil water. - Agr. Water Manage. 96: 790-798, 2009.

Souza T.C., Magalhães P.C., Castro E.M. et al.: Corn root morphoanatomy at different development stages and yield under water stress. - Pesqui. Agropecu. Bras. 51: 330-339, 2016.

Souza T.C., Magalhães P.C., Pereira F.J. et al.: Leaf plasticity in successive selection cycles of "Saracura" maize in response to periodic soil flooding. - Pesqui. Agropecu. Bras. 45: 16-24, 2010.

Souza T.C., Magalhães P.C., Mauro de Castro E. et al.: The influence of ABA on water relation, photosynthesis parameters, and chlorophyll fluorescence under drought conditions in two maize hybrids with contrasting drought resistance. - Acta Physiol. Plant. 35: 515-527, 2013.

Tarek A.E.E., Sadak M.S., Dawood M.G.: Improving drought tolerance of quinoa plant by foliar treatment of trehalose. CIGR J. 2017: 245-254, 2017.

Tounekti T., Mahdhi M., Al-Turki T.A., Khemira H.: Water relations and photo-protection mechanisms during drought stress in four coffee (Coffea arabica) cultivars from southwestern Saudi Arabia. - S. Afr. J. Bot. 117: 17-25, 2018.

Urban J., Ingwers M., McGuire M.A., Teskey R.O.: Stomatal conductance increases with rising temperature. - Plant Signal. Behav. 12: e1356534, 2017.

van Kooten O., Snel J.F.H.: The use of chlorophyll fluorescence nomenclature in plant stress physiology. - Photosynth. Res. 25: 147-150, 1990.

Van Oosten M.J., Pepe O., De Pascale S. et al.: The role of biostimulants and bioeffectors as alleviators of abiotic stress in crop plants. - Chem. Biol. Technol. Agr. 4: 5, 2017.

$\mathrm{Xu}$ Z., Zhou G.: Responses of leaf stomatal density to water status and its relationship with photosynthesis in a grass. J. Exp. Bot. 59: 3317-3325, 2008.

Yamauchi Y.: Integrated chemical control of abiotic stress tolerance using biostimulants. - In: Andjelkovic V. (ed.): Plant, Abiotic Stress and Responses to Climate Change. Pp. 13. InTechOpen 2018.

Yan W., Zhong Y., Shangguan Z.: Evaluation of physiological traits of summer maize under drought stress. - Acta Agr. Scand. B-S. P. 66: 133-140, 2016.

Zandalinas S.I., Mittler R., Balfagón D. et al.: Plant adaptations to the combination of drought and high temperatures. Physiol. Plantarum 162: 2-12, 2018.

Zhao D.-Q., Li T.-T., Hao Z.-J. et al.: Exogenous trehalose confers high temperature stress tolerance to herbaceous peony by enhancing antioxidant systems, activating photosynthesis, and protecting cell structure. - Cell Stress Chaperon. 24: 247-257, 2019.

Zhao W., Sun Y., Kjelgren R., Liu X.: Response of stomatal density and bound gas exchange in leaves of maize to soil water deficit. - Acta Physiol. Plant. 37: 1704, 2015.

Zhou M.-L., Zhang Q., Sun Z.-M. et al.: Trehalose metabolismrelated genes in maize. - J. Plant Growth Regul. 33: 256-271, 2014.

(C) The authors. This is an open access article distributed under the terms of the Creative Commons BY-NC-ND Licence. 